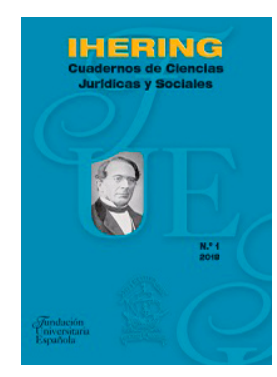

Ihering. Cuadernos de Ciencias Jurídicas y Sociales $\mathrm{N}^{\mathrm{o}} 3$

Año: 2020

e-issn: 2660-552X

DOI: https://doi.org/10.51743/ihering.34

(c) (1) \& 8

\title{
Tiresias en el Estado de Derecho: la Era de Hooper. Retorno a Brideshead, hasta que las voces humanas nos despierten
}

Tiresias in the Rule of Law: the Hooper Era. Return to Brideshead, until human voices wake us up

\section{ENRIQUe SAN Miguel PÉREZ}

Universidad Rey Juan Carlos. Madrid

\section{Resumen}

La novela de Evelyn Retorno a Brideshead, publicada en 1945, analiza la transformación institucional del Reino Unido desde una visión imperial a la fundación de su contemporáneo Estado social, con Charles Ryder y su asistente Hooper como símbolos de una nueva cultura política democrática: la cultura de los derechos sociales.

\begin{abstract}
Evelyn Waugh's novel Brideshead Revisited, published in 1945, includes the institutional transformation of United Kingdom from an imperial conception to the build of a contemporary social State, with Charles Ryder and his assistant Hooper as the symbol of a new democratic political culture: the culture of social rights.
\end{abstract}

\section{Palabras claves}

Estado de Derecho. Estado Social. Democracia. Evelyn Waugh. Retorno a Brideshead. 
ENRiQue SAN Miguel PÉREZ

\section{Key Words}

Rule of Law. Social Estate. Democracy. Evelyn Waugh. Brideshead Revisited.

\section{EL ARTE APLICADO DE EVELYN WAUGH Y LA IRRUPCIÓN EN LA HISTORIA DE LOS ANTIGUOS ALUMNOS DE LA ESCUELA PÚBLICA}

Un mundo nació en 1945 con una monumental novela cuyo tema central, como en sus primeras páginas dice su propio autor, Evelyn Waugh, es el recuerdo. $\mathrm{Y}$ ese mundo nacido hace ahora 75 años sigue siendo el nuestro. Para Charles Ryder, historiador graduado en Oxford y "pintor arquitectónico", movilizado como oficial británico durante la II Guerra Mundial, narrador, protagonista de la novela y trasunto del autor londinense, ese mundo obedece a una muy específica denominación: la "Era de Hooper", en honor a su ayudante de campo, un leal, tosco, honesto, sólido y lúcido laborista, convencido militante en el cambio que se avecina cuando concluya una contienda que hace imposible que el mundo vuelva a ser el mismo.

Para los lectores devotos de la novela, una obra de culto desde su culminación y edición durante los últimos episodios del más devastador conflicto bélico de la historia, una Era que comienza, precisamente, cuando en la primavera de 1944, Charles Ryder es objeto de un traslado nocturno con su unidad hacia un lugar secreto en el interior de Inglaterra para descubrir a la mañana siguiente que su destino era un escenario que le resultaba especialmente familiar y querido: el castillo de Brideshead, el hogar de la familia Marchmain, una aristocrática dinastía católica que había ocupado su vida durante las décadas más decisivas de una existencia que, cuando la novela se abre a la lectura, y Charles Ryder ha cumplido ya los 39 años, "empieza a envejecer".

Numerosas interpretaciones de una novela muy poderosamente autobiográfica - sobre todo en su primera parte, la celebérrima Et in Arcadia Ego- se han centrado, en buena lógica, en la figura portentosa de Evelyn Waugh y la denominada por Humphrey Carpenter la Brideshead Generation, seguramente uno de los grandes paradigmas de generación de intelectuales con plena conciencia de serlo que nace en la vida universitaria, 
y que habría de brindar episodios tan denotativos del sentido de una vivencia generacional como la que se produjo por ejemplo en el New College el día que la Newman Society organizó una conferencia de Gilbert Keith Chesterton y resultó que en esa conferencia se conocieron Evelyn Waugh y Harold Acton ${ }^{1}$.

Hace falta mucho más que la aparente indiferencia de los dioses para ignorar episodios de tanto voltaje cultural. Y ni que decir tiene que también el propio Harold Acton, uno de los más íntimos amigos de Evelyn Waugh, considerado de manera errónea como el modelo del decadente pero muy activo salonnier de exquisito gusto y juicio ágil, severo y mordaz que en la novela reproduce Anthony Blanche, habría de recordar a Evelyn Waugh como "un pequeño fauno", igual a los que él mismo había contemplado en Nápoles, el Museo Vaticano y las fuentes italianas, "esos ojos tan separados, la expresión siempre próxima al sobresalto bajo las arqueadas cejas, los labios sensualmente curvados, los mechones de cabello como jacintos...", pero un fauno casi domesticado por su amor por la Edad Media y la tutela de los círculos más afines a Chesterton, quienes "ya por entonces miraban hacia Roma", al mismo tiempo que "coqueteaba con la política conservadora" y "peroraba enérgicamente sobre la unidad británica" ${ }^{2}$. Harold Acton definía ya, con la mirada excepcionalmente sensible y original de uno de los mayores hijos de su siglo, los rasgos denotativos de un escritor que pretendía asumir desde su juventud la titánica tarea de conjugar la creación, el testimonio religioso, la maduración e irradiación de un pensamiento, y la acción

${ }^{1}$ CARPENTER, H.: The Brideshead Generation. Evelyn Waugh \& His Generation. London. 1989, p. 70.

${ }^{2}$ ACTON, H.: Memorias de un esteta. Valencia. 2010, pp. 212-214: "Hiciera lo que hiciera, poseía un marcado estilo propio, un sello reconocible que lo distinguía de cuanto le rodeaba. He conocido a otros faunos, pero a ninguno con tanta honradez artística. Nuestra amistad ha resistido muchos embates nacidos de los comentarios de maliciosos conocidos comunes que insistían en identificarme con sus más grotescos personajes. Es perfectamente natural que al trazar el perfil de sus héroes un novelista se inspire en las peculiaridades de sus amigos ya que estás destacan notablemente entre sus centros de atención y sus características han de seguir interesándole por fuerza mientras siga tratándolos. El suyo es un arte aplicado, y no puede depender por entero de la imaginación. Evelyn siempre regresa a mi vida en momentos propicios para ambos. Sólo hay una fisura en nuestra relación: carece de oído musical y apenas distingue una melodía de otra...". 
política. Una ambición hercúlea, pero también lúcida: la refundación política del conservadurismo británico a partir de una visión cristiana católica, unitaria e ilustrada conforme al canon chestertoniano.

Familiares y biógrafos, es decir, muchas veces lo mismo y los mismos, encuentran poderosos argumentos familiares para describir la maduración veloz, y también feraz, del joven enviado por Arthur Waugh a Oxford en enero de 1922. Y, junto a su rebelión adolescente, su languidez y la afición a la bebida, rasgos que habrían de originar un indiscutible impacto en sus modestas calificaciones, una propensión ésta última que habrían de heredar sus también lúcidos descendientes), su nieto Alexander, quizás y si cabe el más lúcido entre ellos, detecta en el deterioro de su relación con su padre uno de los motores de su apasionado deslumbramiento por el brillo de la Arcadia oxoniense, un hecho que sin embargo no destaca en la misma medida sus biógrafos, que Alexander Waugh encuentra más inquietos por averiguar la naturaleza de las relaciones que su abuelo Evelyn mantuvo en Oxford que por internarse en la conformación y despliegue de su ideal político e institucional como historiador ${ }^{3}$. Porque, cuando de analizar el pensamiento y la creación de Evelyn Waugh se trata, forzoso resulta recordar que era un historiador institucional y de las culturas políticas, capaz de desplazarse desde la entraña de la contemporaneidad hacia la Antigüedad tardía. Un convencido morador del proyecto occidental de civilización.

El interés que suscita Retorno a Brideshead ha tendido a centrarse en la formidable crisis británica de Entreguerras, cuando una nación que se había impuesto en una contienda tan terrible como la justamente conocida desde entonces como "Gran Guerra" se enfrentó a una situación tan cierta como engañosa: se había impuesto militarmente en el conflicto, y su sistema imperial se veía enriquecido por nuevos mandatos que consolidaban su posición de liderazgo en el mundo; pero la sociedad británica se encontraba exhausta, las arcas de su Tesoro vacías, y las exigencias políticas de su ciudadanía y de sus territorios se multiplicaban en un modo que hacía presagiar que nada sería igual que antes del 28 de junio de 1914.

${ }^{3}$ WAUGH, A.: Fathers and sons. London. 2005, pp. 172 y ss., y HASTINGS, S.: Evelyn Waugh. A Biography. London. 2002, pp. 83 y ss. 
Como recordaba en el primer volumen de sus memorias Harold Macmillan, de acuerdo con sus conversaciones con Winston Churchill, el triunfo en la I Guerra Mundial había representado para el Reino Unido la cuarta victoria consecutiva en apenas dos siglos sobre "aquellos que habían intentado establecer una tiranía militar sobre Europa". Para quien fuera primer ministro británico, eso comportaba un auténtico "récord de persistencia" que no conocía igual a lo largo de toda la historia. Pero, como él mismo reconocía, a pesar de su avezado carácter de analista, historiador, hombre de letras y editor, "apenas sospechábamos que todo esto se perdería en apenas una generación". Por muchos conceptos, a pesar del entusiasmo crédulo de una élite más poseída que nunca del sentido casi misional de la presencia de Gran Bretaña en el mundo y en la historia, su imperio y ella misma se contaban también entre los vencidos cuando el 11 de noviembre de 1918 se produjo el $\operatorname{armisticio~}^{4}$.

Las primeras novelas de Evelyn Waugh, y seguramente entre todas la primera, Decadencia y caida (Decline and fall, 1928), publicada cuando su autor contaba apenas 25 años, representa un excelente examen de la sociedad de su tiempo, el del tránsito del segundo mandato de Stanley Baldwin al primer gobierno largo de los laboristas, con Ramsey MacDonald ocupando por segunda vez el 10 de Downing Street con el sustento de los liberales. Un examen que trasciende más allá del humor, e incluso de la ironía, para internarse en el más abierto sarcasmo. Pero un sarcasmo lúcido: nadie se atrevió a diseccionar la sociedad británica como Evelyn Waugh, y a diseccionarla, además, con claridad y concisión. La figura de Peter Grimes, amigo del protagonista de la novela, Paul Pennyfeather, siempre llamado "el antiguo alumno de una escuela pública", viene a testimoniar que, frente a la finitud de los victorianos y de los eduardianos, ha emergido una raza de hijos de la clase media denotada por un rasgo esencial: la inmortalidad ${ }^{5}$. Exactamente tres décadas antes de que

\footnotetext{
${ }^{4}$ MACMILLAN, H.: Winds of Change. 1939-1945. London. 1966, p. 106.

${ }^{5}$ WAUGH, E.: Decadencia y caída. Barcelona. 1986, pp. 217-218: "...pertenecía a la raza de los inmortales. Era una fuerza vital. Sentenciado a muerte en Flandes apareció en Gales. Ahogado en Gales, surgía en Sudamérica; tragado por el negro misterio de Egdon Mire, aparecería en alguna otra parte; en cualquier momento, quitándose de los miembros los re-
} 
Giuseppe Tommasi de Lampedusa lo dijera en El gatopardo (Il gattopardo, 1958), Evelyn Waugh expresa la certeza de que la aristocracia británica no tiene asegurada la inmortalidad que el príncipe de Salina le adjudica únicamente a la Iglesia, pero no a la nobleza. El escritor inglés establece la misma distinción, pero en su caso adjudica esa misma inmortalidad a la clase media. Es difícil prefigurar, tan pronto en el tiempo, y de manera tan creativa, el sentido que cobrará la historia, y muy especialmente la historia británica y europea.

En libros como el siguiente, Cuerpos viles (Vile Bodies, 1930), aparecido además en una fecha también sumamente emblemática, apenas unos meses después del crack bursátil, Evelyn Waugh describía una atmosfera singular, sin precedentes reconocibles en su apacible niñez, o en su adolescencia en una sociedad en guerra, no digamos en la Arcadia universitaria, cultivada, pero también militante, y denotada por la apatía, la indolencia y la irresponsabilidad. Esa visión crítica se resume en el concepto "fiesta": las élites de una Gran Bretaña sumida en una terrible crisis han optado por pretender ignorar la realidad entregándose a una celebración tan previsible como tedio$\mathrm{sa}^{6}$. Evelyn Waugh procede a una severa censura de actitudes y estilos. Y el mismo aborda, también en plena juventud, una tarea a la que consagrará el resto de su vida: el abandono del mundo.

secos tegumentos de la tumba. Con toda seguridad había seguido el cortejo báquico en la distante Arcadia, y tocado los caramillos míticos junto a arroyuelos olvidados, y enseñado a los pueriles sátiros el arte del amor. ¿No había sufrido, impertérrito, las temibles condenas de todos los dioses ofendidos de todas las historias: fuego, azufre y prolongados terremotos, plagas y pestes? ¿No había permanecido en pie, como un centinela pompeyano, mientras las ciudadelas del llano caían en ruinas en su derredor?...".

${ }^{6}$ WAUGH, E.: Cuerpos viles. Barcelona. 1990, pp. 132-133: "(... Fiestas de máscaras, fiestas salvajes, fiestas victorianas, fiestas griegas, fiestas del salvaje Oeste, fiestas rusas, fiestas de circo, fiestas en las que uno tenía que disfrazarse de cualquier otro, fiestas a las que se concurría casi desnudo, en el bosque de St. John; fiestas en apartamentos y en estudios y en casas y en barcos y en hoteles y en clubes nocturnos, en molinos y en piscinas; tés en la escuela, donde se comía bollos y merengues y cangrejo en lata; fiestas en Oxford, donde se bebía jerez y se fumaban cigarrillos turcos; aburridos bailes en Londres y cómicos bailes en Escocia y desagradables bailes en París... toda esa sucesión y repetición de humanidad apiñada... Esos cuerpos viles...)". 


\section{DE LA ARCADIA A LA DEMOCRACIA}

Fue Retorno a Brideshead, sin embargo, la obra en donde el pequeño escritor consiguió convertirse en uno de los grandes narradores de su tiempo. El subtítulo del libro, que anuncia en su primera traducción al español, la bonaerense de 1948, unas memorias sagradas y profanas del capitán Charles Ryder, anuncia ya la integración entre dos mundos: el del propio capitán, un historiador y artista formado en Oxford y procedente de la muy acomodada élite urbana londinense, y el de su ayudante, Hooper, procedente de las Midlands inglesas, allí donde el proceso de industrialización ha promovido la configuración de una clase trabajadora cuyo protagonismo en el esfuerzo de guerra, y tanto en el frente como en la retaguardia, ha resultado determinante para la inconmovible resistencia británica, y será igual de decisiva en su victoria final.

La llegada a Brideshead, la exquisita residencia de los Marchmain en el Oxfordshire (aunque el Castle Howard utilizado tanto para la serie de televisión realizada por Charles Sturridge y Michal Lindsay-Hogg en 1981 como para la película dirigida por Julián Jarrold en 2008 se encuentra mucho más al Norte, cerca de York) merece de Hooper una valoración que transmite al lector de manera muy nítida la conciencia que ambos oficiales británicos albergan, por no decir ostentan, respecto de su dispar identidad y procedencia. Hooper tiene y tendrá siempre en la novela, además, la virtud, admirada por Ryder, de expresarse en todo momento con suma claridad:

"El cuartel general de la brigada llega la semana que viene. Esta casa es un barracón de primera. He estado husmeando un poco. Demasiados adornos, diría yo. Y una cosa muy rara: hay una especie de templo católico anexo a la casa. He mirado dentro y estaban oficiando alguna ceremonia; no había más que un sacerdote y un anciano. Me sentí un poco fuera de lugar. Es más tu mundo que el mío" 7 .

\footnotetext{
${ }^{7}$ WAUGH, E.: Retorno a Brideshead. Las memorias sagradas y profanas del capitán Charles Ryder. Buenos Aires. 1948, p. 21. En el prólogo a la edición de 1959 (Barcelona. 1992, pp. 9-10), redactado en Combe-Florey, el novelista inglés rememora la elaboración de la novela en 1944, en plena contienda mundial, y reconoce que "escribí con una fruición que no era propia de mí, pero también con impaciencia para volver al
} 
Al igual que Charles Ryder, Evelyn Waugh había estudiado Historia. Y su mirada, siempre literaria y cívica, humana y política, adopta la perspectiva del historiador. El mismo sentido de la pasión y del equilibrio, de la contención y del compromiso. La conciencia de ser el tiempo y en el tiempo. Todo el ser, y todo el tiempo. En sus inacabadas memorias, apenas iniciadas con Una educación incompleta, él propio novelista recuerda cómo Maimie Lygon habría de considerar sus años estudiantiles como no malgastados ni un solo día, después de leer en Madresfield grabado en una de las fuentes del jardín que "se malgasta el día en que no ríe uno". Pero, en un arranque de lucidez y honestidad, Evelyn Waugh recuerda también todas las dificultades a las que habría de hacer frente en sus años en Oxford ${ }^{8}$.

La potencia de la historia de la fascinante familia Marchmain, o la tristeza de la vida del propio Charles Ryder, revestida de un cínico sentido del humor cuando se afronta una personalidad tan singular como la del propio padre del protagonista, un contrapunto perfecto de las atormentadas naturalezas del marqués y de Lady Marchmain, y no digamos de sus singulares vástagos, desde el mayor, "Bridie", a la pequeña, la extraordinariamente sagaz Cordelia pasando, por supuesto, por Julia y Sebastián Flyte, hijos de un tiempo que se obstina en reconocerlos como tales, ocupa sin duda buena parte de la novela. Como la personalidad de figuras como Antoine Blanche, Cara y, en menor medida, el primo Jasper, Hardcastle y su hermana Celia, Ryder por matrimonio, o Samgrass y, después, el enigmático Kurt. Pero Evelyn Waugh les trata como figurantes. Su objetivo, como él mismo señala

combate. Era una época deprimente, de privaciones y continuas amenazas -la época de la sopa de judías y el lenguaje llano-, y en consecuencia el libro está teñido de un matiz de sibaritismo, de nostalgia por la buena comida y los buenos vinos, por los esplendores de un pasado reciente, y por un lenguaje retórico y adornado, que ahora, con el estómago lleno, encuentro de mal gusto...".

${ }^{8}$ WAUGH, E.: Una educación incompleta. Autobiografía parcial. Barcelona. 2007, p. 304: "Sería falsear mi vida de estudiante si la describiera como una diversión ininterrumpida y trufada de risas. Hubo trifulcas y hubo fases de auténtico crápula, así como pasajeros arranques de desesperación adolescente (...) Hubo también deudas acuciantes.El lector habrá hecho bien en preguntarse... cómo pude permitirme la vida que he descrito. Y es que no me la pude permitir...". 
en el prólogo a la primera edición de la obra, es describir la acción de la Gracia en la vida de las personas.

Por eso los figurantes lo son, y perfectos, en el teatro de una historia que, por muchos conceptos, se enfrenta a sus más decisivos episodios, superadas "the follies of the victory", expresión con la que Winston Churchill se refería al convencido entusiasmo con el que la ciudadanía de las potencias aliadas acogió la conclusión de la Gran Guerra (y de la gripe de 1918) y la consiguiente expansión de un sentimiento de casi adolescente creencia en que la paz, la seguridad y la prosperidad se instalarían en el mundo para siempre ${ }^{9}$. Como muy bien dice Charles Ryder, son "huérfanos de la tormenta". La tormenta que se aproximaba en el primer volumen de La Segunda Guerra Mundial de Winston Churchill. La tormenta que habría de transformar el mundo para convertirse en el pilar del tiempo en el que todavía habitamos. Seguramente, la más decisiva tormenta de la historia.

Una historia, la de la Gran Bretaña en donde Antonhy Blanche recita Tierra baldía de T. S. Eliot, que comienza en 1922, en pleno impacto del final de la Guerra de Independencia de Irlanda, con el más que secular mapa partidario sometido a profundas corrientes de cambio mientras los viejos usos protocolarios sometían a la acción ejecutiva del gabinete a constantes interferencias, reminiscencias de la soberbia imperial ${ }^{10}$, y concluye en 1944 en las vísperas del Desembarco de Normandía. La Gran Bretaña que comienza una nueva etapa de su historia cuando David Lloyd George, el popular e indómito premier liberal galés (no han vuelto a conjugarse ni siquiera dos de estas tres premisas) se encuentra a punto de ser aniquilado por la conjura del Carlton Club, pero sobre todo sometido a una virulenta campaña de desprestigio por parte de todos los estamentos del sistema político británico, como habría de recordar todavía en vida del león galés Tony Benn ${ }^{11}$, y termina en el gobierno de unidad que preside Winston Churchill, pero en el que ya Clement Attlee, como viceprimer ministro, dibuja la estrategia de aplicación del

\footnotetext{
${ }^{9}$ CHURCHILL, W.: The Second World War I. The Gathering Storm. London. 1948, pp. 3 y ss.

${ }^{10}$ HENNESSY, P.: The Hidden Wiring. Unearthing the British Constitution. London. 1995, pp. 19 y ss.

${ }^{11}$ BENN, T.: The Benn Diaries. Selected, Abridged and Introduced by Ruth Winstone. London. 1996, pp. 61-62.
} 
programa laborista que no pudo llevar a término Ramsey MacDonald cuando por dos veces desempeñó la primera magistratura política electiva del Reino Unido ${ }^{12}$.

En el marco de una monarquía parlamentaria, casi de la monarquía parlamentaria por excelencia, las apenas dos convulsas décadas que cubre la novela se enfrentan al eclipse liberal tras la dimisión de Lloyd George en octubre de 1922, las elecciones de la división liberal del 22 de noviembre de ese mismo año, y la conversión del laborismo de Ramsey MacDonald en el partido del turno cuando tras las elecciones del 6 de diciembre de 1923 su efímero gobierno, al que seguirá el mandato conservador que lidera Stanley Baldwin tras obtener una amplísima mayoría absoluta en las elecciones siguientes del 29 de octubre de 1924, se convirtió en la fuerza consolidada como alternativa en las tareas ejecutivs tras su triunfo en las elecciones del 30 de mayo de 1929. Es decir: se produjeron tres elecciones en tres años (1922, 1923, y 1924) con tres partidos sucesivamente instalados en las tareas de gobierno (liberales, laboristas y conservadores) con tres primeros ministros de procedencias nacionales también diversas (David Lloyd George, galés; Ramsey MacDonald, escoces; Stanley Baldwin, inglés), antes de que se procediera a una nueva estabilización del sistema político, institucional y partidario de Gran Bretaña. Un sistema que se avecina ya a su centenario.

También es el tiempo de la huelga general del 4 al 13 de mayo de 1926, que movilizará las energías de los jóvenes estudiantes oxonienses más afines a Charles Ryder y Sebastián Flyte. Un tiempo que un severo Harold Macmillan, también historiador graduado en Oxford, quien habría de debutar como MP recién cumplidos los 30 años, en el 1924 por tantos conceptos fundacional, califica como el tiempo político en donde los tres grandes partidos habrían de comportarse con "irresponsabilidad y ceguera", pavimentando el camino hacia la crisis y, finalmente, la propia guerra ${ }^{13}$.

Pero más claro es Anthony Eden en sus memorias cuando describe la evolución que experimentó el conservadurismo británico cuando el laboris-

\footnotetext{
12 THOMAS-SYMONDS, N.: Attlee. A Life in Politics. London. 2012, pp. 35 y ss.

${ }^{13}$ MACMILLAN, H.: The Blast of War. 1939-1945. London. 1967, p. XII.
} 
mo se impuso por primera vez en escaños (aunque no en sufragios) tras las elecciones del 30 de mayo de 1929, y formaron gobierno con la anuencia de los liberales de Lloyd George, que renunciaron a entrar en cualquier gobierno, pero también permitieron la investidura de Ramsey MacDonald, debiendo Stanley Baldwin pasar a la oposición:

"Después de una derrota un partido político ha de sufrir a menudo un proceso de reajuste para consolidarlo y fortalecerlo. Y así le ocurrió en aquella época al Partido Conservador. Tuvimos que desembarazarnos de viejos resabios. Como era cosa corriente en aquellos tiempos, en una reunión del partido celebrada para discutir sobre la jefatura, uno de los que criticaban a Stanley Baldwin se quejó de que 'en todas las comidas del partido hemos de oír críticas contra él'. Noel Skelton gritó desde la tribuna: '¿Y qué es lo que se oye en los barrios bajos?'. Quizá sabíamos de esos barrios menos de lo que creíamos, pero nos dábamos cuenta al menos de que era su confianza lo que debíamos conseguir y de que había que mejorar sus condiciones de vida. Queríamos llegar a una democracia poseedora de bienes individuales, aunque poca gente en nuestro partido tenía mucha confianza en nuestra fe y la oposición nos ridiculizaba" ${ }^{14}$.

Evelyn Waugh fue capaz de captar la singular atmósfera de este nuevo Reino Unido en sus primeras novelas. Pero no fue tan capaz de asimilar y ordenar los perfiles de este tiempo por sí mismo. La serenidad intelectual de antaño, la "languidez" evocada y añorada como emblema de Et in Arcadia Ego, sucumbió durante años ante las exigencias de tiempos sin excusas ni concesiones. En Noventa y dos días (Ninety-two days. A Journey in Guiana and Brazil. 1932, 1934), en donde relata su viaje a América en 1932, el novelista de Hampstead habría de referirse a la capacidad de un largo viaje con destino a lugares distantes como forma de redescubrir, por no decir, descubrir, placeres como el de la lectura: "...había leído muchos libros por numerosas razones: para adquirir información, por la curiosidad de saber de qué trataban, por cortesía debido a que conocía al autor... he leído libros por trabajo, porque me pagaban por escribir una reseña". Pero el escritor, todavía un joven que no había alcanzado la treintena, y con ella la edad de la elegancia, comenzaba a leer por de-

${ }^{14}$ EDEN, A.: Memorias. Frente a los dictadores. 1923-1938. Barcelona. 1962, p. 27. 
leite, un placer desconocido desde hacía más de diez años. La Gran Bretaña imperial desplegaba una vertiente desconocida antes de la gestación y maduración de la Brideshead Generation ${ }^{15}$. Comenzaba a manifestarse, y de manera decisiva. el Charles Ryder que como historiador habría de consignar el nacimiento de la Era de Hooper.

Y con enorme lucidez, en Hombres en armas (Men in Arms, 1952), primer volumen de su trilogía final, Espada de honor (Sword of Honour), que completan Oficial y caballero (Officers and Gentlemen, 1955) y Rendición incondicional (Unconditional surrender, 1961), Evelyn Waugh analizaría también la realidad de la Europa de los totalitarismos y del estallido de la II Guerra Mundial en términos denotativos de su capacidad para conjugar la perspectiva del historiador y la experiencia del hombre de su tiempo para modelar una interpretación única del alzamiento de la modernidad contra un enemigo "enorme y odioso":

"Sólo siete días antes había abierto el periódico por los titulares que anunciaban la alianza ruso-alemana. Las mismas noticias que sacudieron a los políticos y a los jóvenes poetas de una docena de capitales trajeron profunda paz a un corazón inglés. Ocho años de vergüenza y soledad habían concluido. Durante ocho años, Guy... había quedado privado de las lealtades que deberían haberle sostenido. Vivía demasiado cerca del fascismo en Italia para compartir la ardorosa oposición de sus compatriotas. Ni lo veía como calamidad ni como renacimientos, sino como una mera improvisación burda. Le disgustaban los hombres que se encaramaban hacia el poder a su alrededor, pero las denuncias inglesas sonaban fatuas e insinceras, por lo que había decidido abstenerse de leer periódicos ingleses durante los últimos tres años. Sabía que los nazis alemanes eran locos y malvados..., pero la crisis de Bohemia, un año antes, le había dejado bastante indiferente. Cuando cayó Praga, supo que la guerra resultaba inevitable. Esperaba que su país entrara en guerra con pánico, por las razones equivocadas o sin razón alguna, con los aliados equivocados, y mostrando una debilidad patéti-

\footnotetext{
${ }^{15}$ WAUGH, E.: Noventa y dos días. La Coruña. 2005, p. 138. En el mismo año 1933, cuando Winston Churchill dio forma de libro a sus recuerdos de su participación en la expedición de Lord Kitchener al Sudán, esta visión imperial se encontraba todavía plenamente presente en el debate público británico, cfr. CHURCHILL, W. S.: La guerra del Nilo. Crónica de la reconquista del Sudán. Madrid. 2003, p. 15: "Espero que la historia de estas páginas pueda servir de ayuda y estímulo a aquellos hombres y mujeres jóvenes que aún mantienen la confianza en el destino de Gran Bretaña en Oriente".
} 
TIRESIAS EN EL ESTADO DE DERECHO

ca. Pero ahora todo se había aclarado espléndidamente. Por fin el enemigo estaba a la vista, enorme y odioso, sin disfraz alguno. Era la Edad Moderna quien se alzaba en armas..." ${ }^{16}$.

Porque, tras la II Guerra Mundial la clase media había emergido para instalarse en el centro de la vida pública. Una fuerza ya decisiva en el período de Entreguerras, aunque sometida a enormes tensiones estructurales, mientras el conservadurismo, como en los tiempos de Robert Peel, se abría a ese electorado, pero no sin grandes controversias internas y auténticas quiebras pacientemente soldadas desde la era victoriana por Benjamín Disraeli y por Lord Salisbury ${ }^{17}$, había por fin consolidado su posición histórica como sustento de la centralidad casi inherente a la reafirmación del proyecto político de un Estado de Derecho que asumía el compromiso de hacer efectivos los derechos económicos y sociales, ampliando los derechos fundamentales al ámbito en el que su ejercicio no era ya meramente teórico, por no decir enunciativo, sino eminentemente aplicado, es decir, imprescindible. La clase media y trabajadora había soportado y sostenido el esfuerzo de guerra, un esfuerzo titánico que se había cobrado un precio exorbitante en dolor, en generosidad abnegada, en sufrimiento y en vidas. Y, ahora, esa misma clase media reclamaba, con la lucidez, la plena conciencia y la convicción de Hooper, y de millones de Hooper con él, la conducción política e institucional de una era que le pertenecía.

Comenzaba la transición de los tories hacia el denominado después "conservadurismo compasivo", que habría de definir la trayectoria pública de sus sucesivos cuatro primeros ministros tras la II Guerra Mundial, Winston Churchill (1951-1955), Anthony Eden (1955-1957), Harold Macmillan (1957-1963) y Alec Douglas-Home (1957-1963), e inspirar el mandato del último de los primeros ministros conservadores que se reconocían en esos planteamientos, pero también orgulloso integrantes de la clase media, hijo de un carpintero de Broadstairs en Kent, historiador, músico y políglota, hijo de

\footnotetext{
${ }^{16}$ WAUGH, E.: Hombres en armas. Madrid. 2003, pp. 117-119.

${ }^{17}$ KYNASTON, D.: A World to Build. London. 2007, pp. 98 y ss., y JAMES, L: The Middle Clas. A History. London. 2006, pp. 414 y ss. Vid. igualmente HURD, D.: Robert Peel. A Biography. London. 2007, pp. 390 y ss.
} 
sus méritos, llamado Edward Heath (1970-1974) La Era de Hooper fue también la suya. Incluso decisivamente suya.

Y probablemente ninguna figura habría de ejemplificar más adecuadamente la transformación del Reino Unido que la de Harold Macmillan, antepasados pastores pertenecientes a la lengua y la cultura gaélica escocesa en la Isla de Arran, cuyos descendientes crearon una prestigiosa editorial y brindaron a la vida pública una presencia formada en el Balliol College de Oxford - "Balliol Made Me, Balliol Fed Me" - refinada, brillante y cultivada, emblema de la cultura política conservadora, del mérito y la determinación personal antes que política ${ }^{18}$. En la figura de Hooper podía reconocerse todo un proyecto de civilización democrática. Evelyn Waugh y Charles Ryder lo sabían. Y, con certeza con enorme melancolía, lo aplaudían.

\section{Yo, TIRESIAS, AUNQUE CIEGO, PALPITANDO ENTRE DOS VIDAS...}

Anthony Blanche recitaba Tierra Baldía de T. S. Eliot para evocar a Tiresias, la gran personalidad clásica, quien se encuentra para siempre ciego como consecuencia del colérico capricho de la diosa Hera (no ha querido admitir que es la más bella entre todas las diosas), pero quien a cambio ha obtenido también la capacidad de ver el futuro. Como Hooper, Tiresias ha padecido la tiranía de una historia despótica y despiadada. Pero, en la Era de Hooper, Tiresias es ya saludado como un héroe. Debilitado, pero instalado en un futuro en el que habita ya. Sabiendo que, por lo tanto, palpita entre dos vidas a las que pertenece, pero no del todo a ninguna de ambas, ajeno a la humana vanidad porque estuvo sentado bajo los muros de Tebas, pero siempre consciente de que anduvo por el infierno de los muertos ${ }^{19}$.

En la Era de Hooper un historiador, diría que particularmente un historiador del derecho, de acuerdo con la propia identidad de la disciplina, palpita siempre, al menos, entre dos universos científicos. Y, sobre todo, al menos, entre dos existencias: la o las que examina y la suya. Y Evelyn Waugh fue

${ }^{18}$ WILLIAMS, C.: Harold Macmillan. London. 2009, pp. 7 y ss.

${ }^{19}$ ELIOT, T. S.: The Waste Land and other poems. London. 1983, pp. 35-36. 
siempre un historiador novelista, como habría de demostrar en su obra sobre la madre del emperador Constantino Elena (Helena, 1950), que el propio escritor inglés considera una experiencia de "desordenada lectura de Historia y Arqueología", en donde, "cuando las autoridades dudan, yo he elegido a menudo lo pintoresco con preferencia a lo plausible... donde han callado, he inventado libremente, pero nada hay... contrario a la auténtica historia". Y en gran medida también en La prueba de fuego de Gilbert Pinfold (The Ordeal of Gilbert Pinfold, 1957), cuya última edición española acompaña una entrevista en donde un Evelyn Waugh que acababa de cumplir los 50 años definía con la lucidez de siempre su circunstancia vital, desaparecidos los placeres de su juventud, pero no los placeres de toda juventud, consistentes sobre todo, en la vivencia asombrada de cuanto es nuevo ${ }^{20}$. El cambio, siempre, actuando como motor y sentido de la historia.

Pero un motor que representa una constante creación. Seguramente Evelyn Waugh entendió el oficio de historiador al modo de Winston Churchill, como un espacio para la participación y la creación y, por lo tanto, como un arte, y no como una actividad científica ${ }^{21}$. Cuando el historiador es sobre todas las cosas un hombre de letras, y como tal hombre de letras su actividad natural, por no decir necesaria, es la escritura, la historia se convierte en un escenario de actuación. Incluso, como en el supuesto de los protagonistas de Retorno a Brideshead, para la representación, Que Anthony Blanche recitara Tierra Baldía desde los tejados de su College, y muy singularmente el fragmento protagonizado por Tiresias, constituye una demostración muy explícita del sentido de la historia que compartían Evelyn Waugh y sus contemporáneos. Anthony Blanche pretendía ser Tiresias en Oxford. Evelyn Waugh va más allá. Tanto Charles Ryder como Hooper son Tiresias felizmente liberados de la ceguera. En la Era de Hooper, el joven procedente de las Midlands contempla el futuro que anhela y cuya certeza se encuentra a su alcance. Pero también Ryder, tras su visita final a la capilla de Brideshead, ha podido conocer

\footnotetext{
${ }^{20}$ WAUGH, E.: Elena. Buenos Aires. 1954, p. 7. Cfr. también La prueba de fuego de Gilbert Pinfold. Madrid. 2007, p. 202: "...consisten en conocer a personas nuevas, ir a sitios nuevos, tener experiencias nuevas, sorprenderse, asombrarse, divertirse...".

${ }^{21}$ LUKACS, J.: Churchill. Visionary. Statesman. Historian. Yale. 2002, p. 103.
} 
con certeza su extraordinario futuro, iluminado por la minúscula llama que brota de una modesta lámpara "de un diseño deplorable".

En el final de sus memorias, Harold Macmillan recordaba al Talleyrand que sostenía que nadie que no hubiera vivido antes de la Revolución Francesa conocía la douceur de la vie para afirmar que, en el caso del Reino Unido, nadie que no hubiera vivido antes del estallido de la Gran Guerra había conocido no tanto la dulzura de la vida como la sensación de paz y de seguridad que había experimentado el pueblo británico. Pero el premier reconocía igualmente, como había hecho siempre durante cuatro décadas de trayectoria pública, que la Gran Bretaña en la que él mismo había servido como primer ministro, la Gran Bretaña de la Era de Hooper, era un país incomparablemente más justo, más democrático, más libre y con más oportunidades que el imperio eduardiano.

E, igualmente, Harold Macmillan recordaba también a sus compatriotas que la Pax Britannica que imponía un imperio mundial cuya supremacía naval había estado incontestada durante siglos había tocado a su fin, y llamaba a sus conciudadanos a un necesario ejercicio de realismo y de adaptación a las nuevas condiciones de un mundo menos seguro, más incierto, más inestable y más cambiante, y al que su país no concurría ya desde una posición de hegemonía. Un país que, al tiempo que trataba de fortalecer su Commonwealth, debía apostar por participar en el proceso de integración europea a la hora de definir su estrategia para la presencia y la influencia en el mundo. De hecho, la posterior publicación de sus diarios, en donde el 11 de mayo de 1951 procede a recoger las brillantes intervenciones de ese gran socialista y europeísta que fue André Philip en defensa del Plan Schuman en la Asamblea Francesa, y sus ataques a la socialdemocracia alemana y al laborismo británico por su posición no favorable a la creación de la Comunidad Europea del Carbón y del Acero y la ratificación del Tratado de París, se saldan con su increencia de que el socialismo europeo "pueda sobrevivir a este asunto" ${ }^{22}$.

Harold Macmillan era perfectamente consciente del comienzo de la Era ${ }^{22}$ MACMILLAN, H.: And the End of the Day. 1961-1963, London. 1977, pp. 521 y ss., y
Diaries. The Cabinet Years. 1950-1957. London. 2003, p. 71. 
de Hooper, y con ella de la plenitud del Estado de Derecho. Para Evelyn Waugh ese ejercicio de adaptación era dudosamente deseable. Pero, sobre todo, no resultaba posible. La lucidez del hombre nacido en 1903, apenas dos años después del fallecimiento de la reina Victoria, y como tal habitante de dos Guerras Mundiales, y participante en la segunda de ellas, convivía con la incapacidad para aceptar un mundo en el que los hombres no hubieran cabalgado junto al príncipe Ruperto, ni se hubieran sentado a calentarse en las hogueras junto al río Xanthos, como Charles Ryder reprochaba a Hooper. El mismo Hooper que dormía plácidamente, mientras él mismo era incapaz ya de descansar, presa de los nervios y de la angustia.

Pero también es cierto que, en los últimos párrafos de la obra, el comienzo de la conversión de Charles Ryder, que el literato une a la guerra y separa de su propia conversión en 1930, en absoluto fruto de los estragos bélicos y vitales y su consiguiente impacto en su conciencia, y sí de un proceso mucho más racional y meditado, viene a dotar de sentido, significado y contenido ese principio de la Era de Hooper. Una Era en donde los laboriosos, probos, honestos y eficaces hijos de la clase media y trabajadora pueden con toda justicia descansar. Porque el tiempo que viene, su organización política y consiguiente definición jurídica, pertenece al ámbito de la ética pública, del proyecto político e institucional compartida, de la democracia como manera de vida. La derrota del totalitarismo nazi-fascista abre una nueva etapa en la historia humana. Y la novedad no se deriva tanto del trazado de una nueva cartografía territorial como de una innovadora cartografía social y emotiva, en donde la rigidez de los antiguos patrones tardovictorianos y eduardianos cede ante la irrupción de una joven, sana y auténtica humanidad. Con certeza, más áspera, menos refinada, y carente de la exquisita sensibilidad de quienes comían huevos de chorlito, merendaban fresas en el campo, bebían y recitaban a T. S. Eliot y Alfred, Lord Tennyson. Pero también más comprometida con el destino del ser humano concreto, más directa y honesta en sus relaciones humanas. La Era que ha traído a la condición humana un sentido de la plenitud vital y existencial sin precedentes en la historia.

Evelyn Waugh sostenía que únicamente cuando se ha perdido toda curiosidad acerca del futuro se está en la edad adecuada para afrontar la idea de escribir una autobiografía, y manifestaba haber deseado contar con la má- 
quina del tiempo de H. G. Wells, pero no para viajar hacia el futuro, "¡la más lóbrega de las perspectivas, si no la más tediosa!", optando por un lento retroceso "flotando suavemente por los siglos", porque es en la propia brevedad de su existencia en donde "tenía la necesidad de un artilugio de estas características, ya que una memoria cada vez menos fiable me enajena a mí mismo, y cada vez más, de mis orígenes y mi experiencia" ${ }^{23}$. Pero nadie mejor que Evelyn Waugh para saber que ese viaje por el túnel del tiempo conducía directamente al mismo futuro soñado por los cruzados que también se habían calentado ante los muros de Acre con el calor que despedía la misma llama sencilla que crepitaba en la capilla de Brideshead ante la contemplación de Charles Ryder. En la Era de Hooper, cada ser humano concreto, cada mujer y cada hombre, puede ser el arquitecto de su propio destino. $\mathrm{Y}$ nadie mejor que el artista Ryder para pintarlo.

Harold Acton decía que su juventud se sustentó sobre una dulce actitud razonable y un risueño escepticismo. La grandeza de la Era de Hooper reside también en haber hecho posible que generaciones de jóvenes que han podido disfrutar de la oportunidad de luchar por sus sueños, y el respaldo de los poderes públicos para hacerlo, no han tenido que renunciar a la dulzura de la razonabilidad y la militancia en ese escepticismo jovial que denota la actitud crítica de una ciudadanía consciente de sus derechos y de sus responsabilidades.

La Era de Hooper, del Estado social y democrático de derecho, de la plenitud democrática, no llegó flotando suavemente, sino tras la derrota del totalitarismo nazi en una terrible, prolongada y sangrienta contienda. Llegó tras la derrota del stalinismo. Llegó unido al proyecto de integración europea. Tiresias ya no palpita entre dos mundos. El futuro que ahora contempla Tiresias aguardaba a que las voces humanas le despertaran, y con él a sus contemporáneos. Y el sonido de ésas voces humanas resulta nítidamente audible en la Era de Hooper en la que seguimos habitando.

\footnotetext{
${ }^{23}$ WAUGH, E.: Una educación incompleta..., p. 6.
} 